\title{
Integration of Tsou Culture into Innovative Poster Creation
}

\author{
Hsiu Ching Laura Hsieh ${ }^{1 *}$, Po Chun Chan ${ }^{2}$ \\ ${ }^{1,2}$ Department of Creative Design, National Yunlin University of Science and Technology \\ *Corresponding author. E-mail: leroserry@gamil.com
}

\begin{abstract}
With the globalization of the modern society, many school children continually absorb foreign popular culture while ignoring the value of their own culture, resulting in the gradual diminishing and disappearing of the rich and historical aboriginal culture. The research explores on the method of applying the culture of Taiwan aboriginal Tsou Laiji tribe on creating posters, and using the folk songs and legendary stories of the Tsou people as innovative elements of creation to produce a series of poster to further help promoting the culture and aesthetics education. The research adopts field study by first undertaking investigation and analysis of the Laiji tribe to extract the local elements of 'people, literature, land, produce, tourism spots' for creation. And finally three visual poster designs were developed for the transmittance of the value and application of the local culture while making the Tsou aboriginal culture sustainable in order to present the beauty of the Taiwan Tsou aboriginal culture.
\end{abstract}

Keywords: aboriginal culture, Tsou Laiji tribe, poster creation

\section{INTRODUCTION}

\subsection{Research background and motive}

The Tsou people currently live around Alishan in Taiwan. In the early times, due to the invasion of the Han ethnic group and the Mandarin (Han) education, Mandarinization has become more severe. Also with the impact of globalization, many school children and tribal members continually absorb outside popular culture and new information, as a result tribal members have overlooked the most beautiful part of their own cultural value, leading to the disappearance and disconnection of their culture. However, most young tribal members have to leave their village to work in order to maintain their livelihood. Therefore, they are not able to commit to reviving their own culture, resulting in a disconnected cultural heritage. The subject of the research is the Taiwan aboriginal tribe of Tsou Laiji tribe. For the purpose of preserving Tsou culture and asset, so that more people will understand the local culture, and in order to maximize the importance of cultural preservation, we went to Laiji Elementary School in the Laiji tribe to conduct field study. We found that the children are always immersed in the traditional nursing rhymes, which are unique and wonderful, and the mood was easy and relaxing. Because of the environmental differences in the aboriginal cultures, different tribes have developed different territorial and cultural characteristics, making traditional music filled with vestiges of life, legendary fairy tales, and historical records, and prompting the designer to use local traditional nursery rhymes and music as the core of design. In terms of materials, the tribe is located in a high-altitude forest, which has diverse ecology of plants and animals that are perfect design elements which can be transformed onto poster designs. By using this method, tribal members can learn how to promote their own culture, turning ethnic elements into fashion aesthetics and calling the tribal members to regard their own culture and aesthetic concept more heavily, plus showing more people the beauty of the Tsou culture.

\subsection{Research goal}

There are two objectives for the research as below:

(1) Explore how to extract Tsou cultural code, geographic elements, and nursery rhymes into poster creation.

(2) Elicit local school children to identify with their own culture and to help the extending and passing on of the aboriginal culture.

\section{LITERATURE REVIEW}

\subsection{Exploration of the current state of Taiwan Tsou culture}

The Tsou tribes mainly live in Alishan village of Jiayi County, and some live in Shinyi Village of Nantou County. They are collectively known as the 'North Tsou'. Those who live in Sanmin District and Taoyuan District of Kaohsiung City are called the 'South Tsou'. The total 
population is around 7000. There is a little difference in terms of the language, dress style, and social organizations between the north and the south Tsou. However, the rituals are entirely different. For example, the 'Triumph Ritual' of the North Tsou is for commemorating the war god, while the 'Zi An Bei Ritual' of the South Tsou is for the spirits of their ancestors. Because the Tsou tribes are widely dispersed, with the North and the South each having its own unique style, the Tsou tribes have developed austere and complex life style and rituals. For this reason, the research would focus mainly on the North Tsou in the Alishan area. The Tsou people currently are facing a cultural crisis with the drastic change in the entire social structure and the continual Mandarinization of the tribal members. Most of the youths are used to the Mandarin ethnic environment, which is a hindering factor to the passing on of the Tsou tradition. Even though there are more and more tribal members wishing to teach the next generation more about their own language, legend, and fairytales, we see that the Tsou youths interact with the Han ethnic people frequently and are less interested in their own tribal tradition. Cultural revival is in a passive state.

\subsection{Tsou Musical Genre}

In the past, the Taiwan aborigine music is strongly connected with life. Be it work, being at home, happiness, anger, sorrow, all of which were expressed in song and dance forming an inseparable relationship between music and daily life (Lui Bing Chuan, 1982) . Aborigine songs and music reflect the tribal life, thoughts and feelings, and they record the history of the entire tribe. Songs have always played a very important role in Tsou peoples' lives in terms of faith, war ritual, legendary fairytales, tribal ethics, or folk activities. And the songs can be sung in monotone or as in the chorus. Wu Rong Shun classified the Alishan Tsou songs and music into 5 categories based on function and characteristics in his book, The Beauty of Taiwan Aborigine Music : Ritual songs, non-ritual traditional (life) songs, edited songs, contemporary creation songs, and church songs.

\subsection{Introduction of Tsou Nursery Rhymes}

Nursery rhymes are categorized as non-ritual songs. Tsou nursery rhymes reflect the history, tradition, and social culture of the Tsou people, conveying the thoughts and feelings of the people, aesthetics ideal and artistic fun (Wu Rong Shun, 2005). All have been produced with the background of the living environment. From the objects described in the nursery rhymes, the social situation at the time can be derived. This is characteristic of nursery rhymes which directly express the forms of nature. That writing life into songs and that nursery rhymes reflecting nature are closely related and will be the main development topic of the research.

\subsection{Semiology and Cultural Transformation Design Method}

The America semiologist, Peirce, explored the relationship between symbols and subjects, classifying it into 3 types: signal, icon, and symbol to explain the relationships among them. The relationships are as follows (Fiske, 1995):

(1) Icon : form or sound is close similarity to the object involved, meaning that there is some objective characteristics of the symbol, the most prevalent are the visual symbols

(2) Index : there is a direct relationship with the object involved. There is a causal relationship and can be logically deduced.

(3) Symbol : there is no similarity nor direct relationship with the object involved but a precedence, agreement, or rule as agreed upon by the people.

Through the corresponding type of symbol and level and culture, there are 3 steps in transforming cultural codes: select cultural style feature, forming design concept, and finish cultural code design. The Tsou culture is the example in the research where in the first phase, meaning is bestowed to the original 'cultural information' to become useful 'design information'. When undergoing designing, taking into account of material, ritual, spiritual aspects of the culture will help 'design thinking transformation' during the design process and turn these elements into the cultural product design (Lin Rong Tai, 2011). In this way, the unique differentiation of the tribal culture is accentuated so that people can identify the origin and story of the tribe and that the core value of the traditional culture is created.

\section{METHOD}

The research is exploring the integration of Tsou culture into innovative poster creation in which the Taiwan's Tsou tribe is the subject. The research mainly adopts the method of field study to undergo exploration by investigating and interviewing Tsou tribal members and expert scholars for research and analysis. The procedure is explained in detail below:

First phase : select Tsou tribe as research subject.

Second phase : actual field investigation and literature review for analysis to construct 'design flow of applying Tsou cultural elements on design creation'.

Third phase : using the above elements to select the extracted Tsou cultural codes.

Fourth phase : transform the extracted cultural codes to a poster design to convey the beauty of the Tsou culture.

The 'design flow of applying Tsou cultural elements on design creation' constructed is illustrated below : 


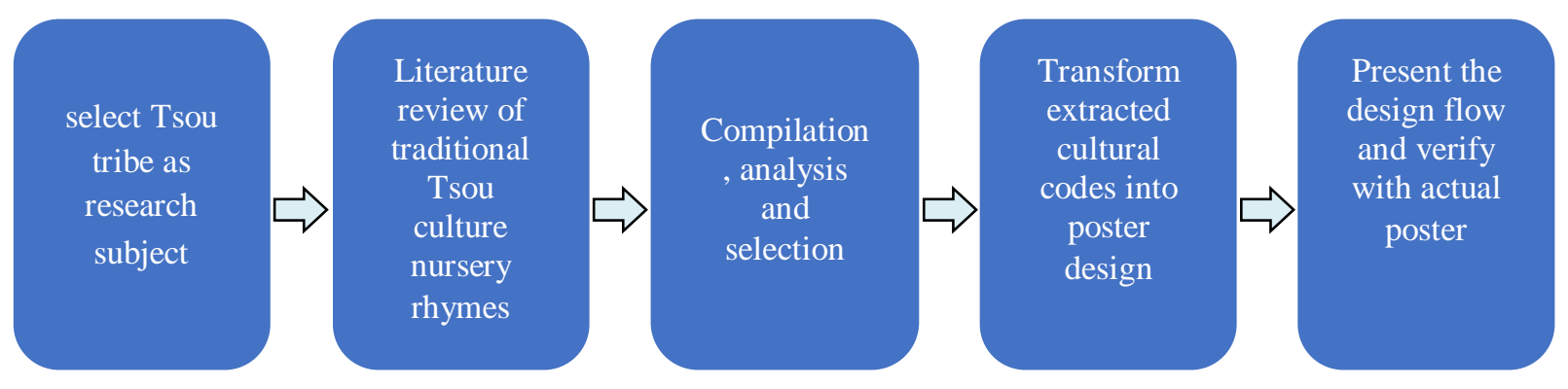

Figure 1. Design flow of applying Tsou cultural elements on design creation

\section{DESIGN RESULTS}

\section{Turning Cultural Code of Tsou Nursery Rhymes}

\section{into Poster Design}

Three songs were selected from the 'Laiji Elementary

School Children's Poem Music Album'. The contents of the songs were analyzed and combined with local elements to be applied to design, transforming the abstract lyrics into creation elements and leading the school children with the purest format to make direct and fast connection for deeper understanding of the beauty of the Tsou culture.

Table 1. Design analysis of the poster 'Meeting the Boar'

\section{Description and Analysis}

Lyrics in Tsou language

yupteulu to fuzu, po 'etngnt 'e av'u

yupteulu to fuzu, cu pono 'e voyu

yupteulu to fuzu, actht 'aveoveoyt
Lyrics Describing the brave Tsou warrior going hunting to protect the family from the interpretation

\section{attacks by the vicious Boar}

\section{Graphics used}

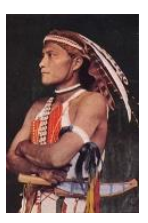

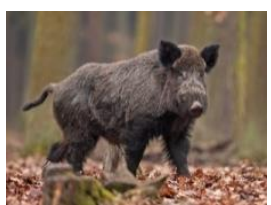

Boar

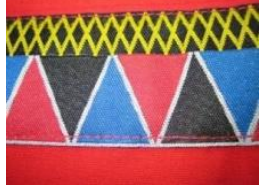

Tsou warrior

Tsou totem 


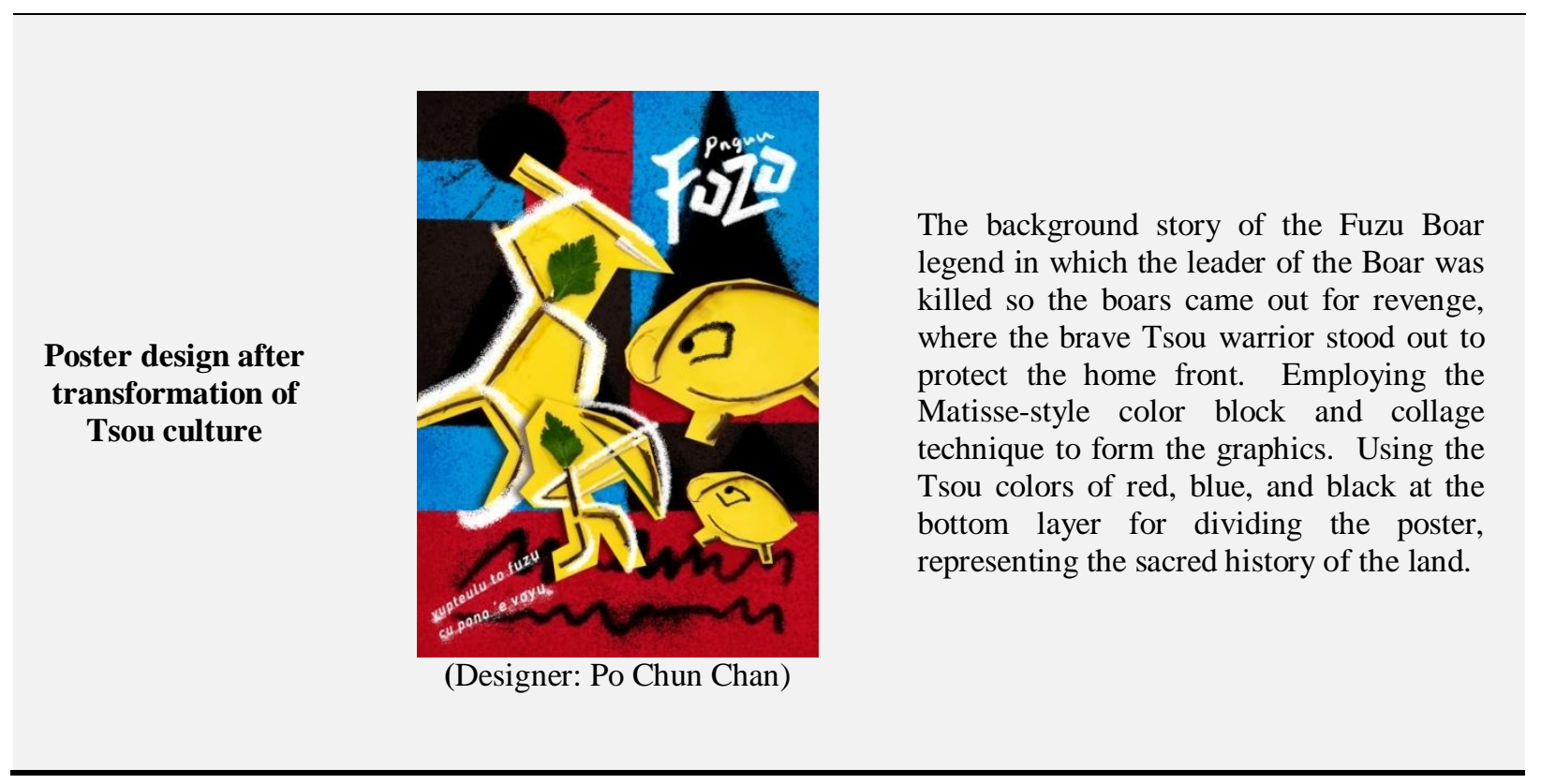

Table 2. Design analysis of the poster 'It's Raining'

\section{Description and Analysis}

Lyrics in Tsou language micu mucht, maine'e 'e zomt

micu much , uhta feongo 'e puktu

micu muchu, o'te meelu mimiyo 'e 'o'oko
Lyrics interpretation
There's ample rain because the Tsou Laiji tribe is located in the high-altitude forest. The lyrics is telling the story of animals returning to their habitats and children not able to go anywhere because it's raining.

\section{Graphics used}
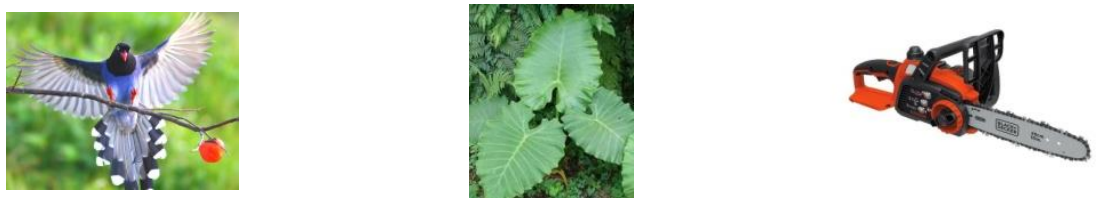

Taiwan Blue Magpie

Giant Elephant's Ear

chain saw 


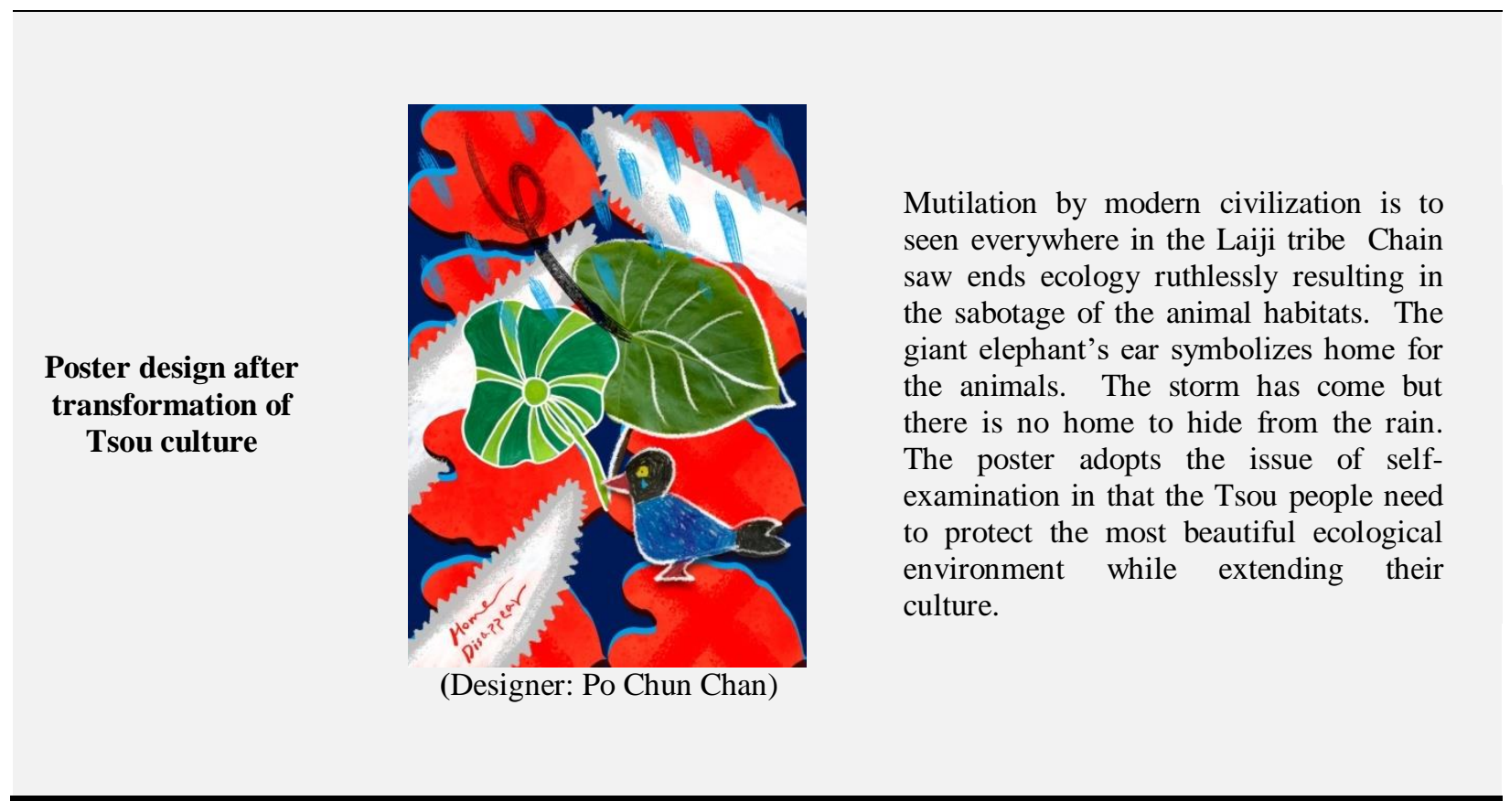

Table 3. Design analysis of the poster 'Gratitude'

\section{Description and Analysis}

'aveoveoyt ta ba'e ton'u, poa man'i 'e tov'oha

poa 'ote avzovzo 'oant, 'aveoveoyt ta a'ke c' oanu

poa yoyosku 'e c'oeha, mafe ho isi ana 'e yoskt

Lyrics in Tsou 'aveoveoyu ta otfonana, poa moyomo 'e yosku

language poa man'i 'e 'oanu, 'aveoveoyu ta teo'fsi'za

mayo ta puzu , poa ya umnu ci h'oyunsova

'aveoveoyt ta hpuhpungu, poa atngaso ta yustho 'oanu

poa 'aveoveoyu ho yontan'e , 'aveoveoyu 'aveoveoyu

The lyrics is describing offering thanks to the Millet Goddess and the River God so
millet and fishing would be bountiful and the Tsou people would not go hungry.
Thanking the Taiwan Blue Magpie for bringing back the tinder so that we are free of
cold and darkness. Thanks for everything the nature bestows upon us in that we are
fed and clothed. Being a Tsou member means happiness.




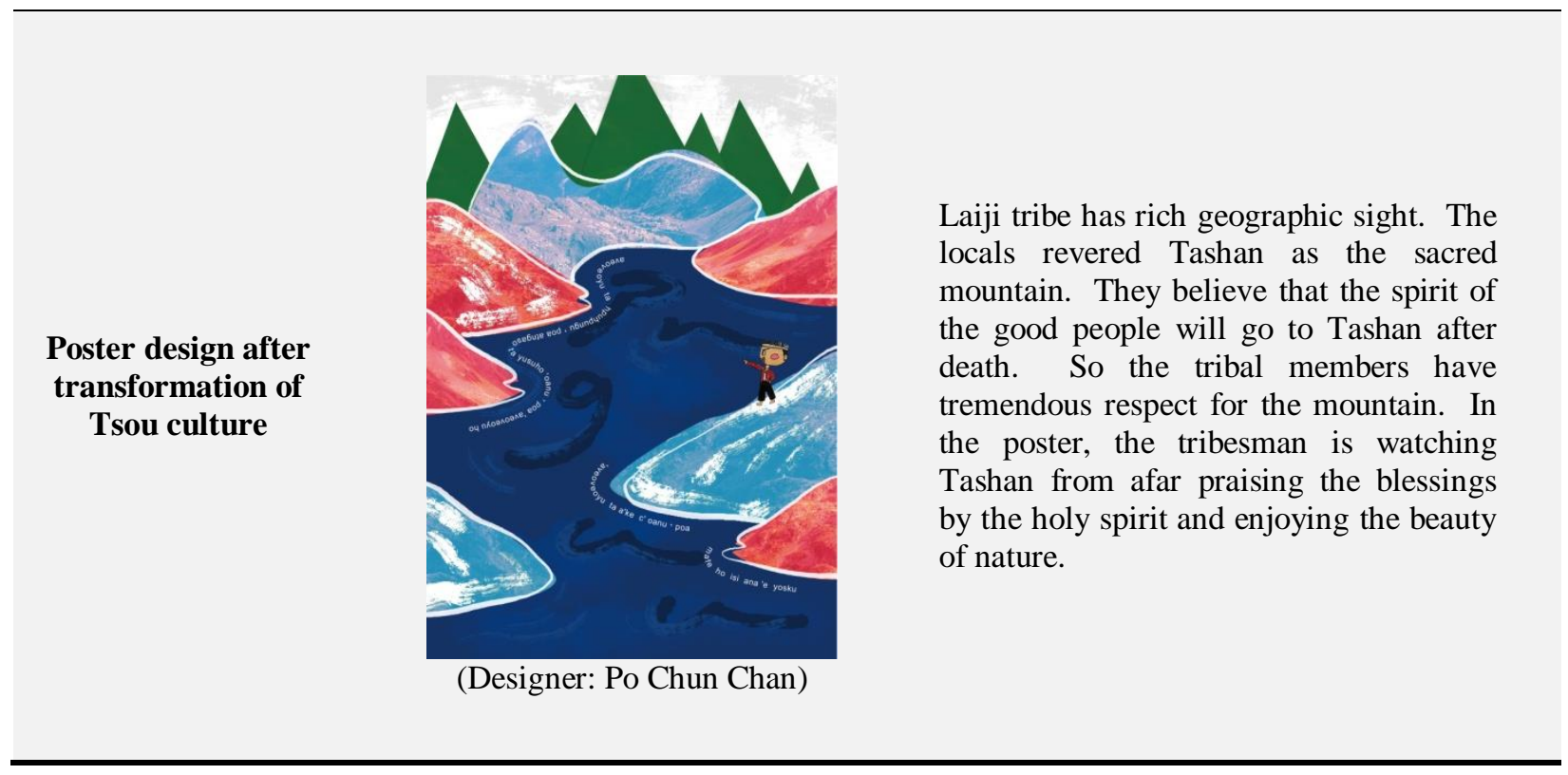

\section{CONCLUSION}

The research executed field study and interviews and integrated literatures with various theories. The Tsou tribe in Jiayi, Taiwan was at the center. During the process of analyzing Tsou cultural codes, transformation of the codes into rich ethnic features was achieved through Tsou nursery rhymes and the familiar everyday life objects. Through the analysis of the poster creation, the plausibility of the 'design flow of applying Tsou cultural elements on design creation' was verified, illustrating that designers can use the creation design flow on actual designing in the future. Helping the designers design a more efficient way so that the Tsou tribal members will identify with their own culture by following tradition and lifestyle in order to pass on the beauty of Tsou culture in this way.

\section{REFERENCES}

[1] Pu, C.C. (2013). Discussion on the relationship between tribal knowledge providers and outsidersTake the Tsou as an example. Journal of The Taiwan Indigenous Studies Association. vol. 3, No. 4, pp. 1-17. Winter.

[2] Lin, R.T. (2011). A Study on Cultural Product Design Process. Journal of Design, vol. 16, No. 4, pp. 1-18.

[3] Pu, Z.Y. (2016). The Ancient Singing of the Ancients - The Arrangement, Singing and Interpretation of the Tsou Ancients. Taiwan Indigenous Studies Review. No. 19, pp. 69-106. Winter.
[4] Liao, T.J. (2005). Action Research for Art Educational Curriculum of Built Environment, JTNUE, vol. 50, pp. 53-78.

[5] Wang, S.Z. (2011). Taiwan's aboriginal society and culture. Linking Publishing Company, Taipei, Taiwan.

[6] Chen, Y.H. (2006). Performance Art and Community Culture : A Case Study of Tsou's Dance and Culture Presentation, Masters Dissertation. Dept of Visual Arts and Design. Nanhua University. Chiayi County.

[7] Lin, K.S. (2015). The Competitions Between Traditional Tribe Structure and Contemporary Community Organizations - A Study of Alishan Tsou Tapangu Community, Masters Dissertation. Institute of Sociology. National Tsing Hua University, NTHU. Hsinchu City.

[8] Tu, M.C. (2017). Laiji Primary School-Children's Poems Singing Music Album. Chiayi, Taiwan. 